\title{
Minimally invasive beating heart technique for redo mitral valve surgery in patients with giant left ventricle
}

hang zhang ( $\sim$ hang8322@163.com )

Zhengzhou University First Affiliated Hospital

Hua shan Xu

Zhengzhou University First Affiliated Hospital

Bing Wen

Zhengzhou University First Affiliated Hospital

Wen-zeng Zhao

Zhengzhou University First Affiliated Hospital

Chao Liu

Zhengzhou University First Affiliated Hospital

Research article

Keywords: Minimally invasive, Beating heart technique, Redo mitral valve surgery, Giant left ventricle

Posted Date: March 5th, 2020

DOI: https://doi.org/10.21203/rs.3.rs-16222/v1

License: (a) This work is licensed under a Creative Commons Attribution 4.0 International License. Read Full License

Version of Record: A version of this preprint was published at Journal of Cardiothoracic Surgery on June 3rd, 2020. See the published version at https://doi.org/10.1186/s13019-020-01171-6. 


\section{Abstract}

Purpose: To analyze the feasibility and efficacy of minimally invasive beating heart technique for redo mitral valve surgery in the cardiac patients with giant left ventricle.

Methods: Eighty cardiac patients with giant left ventricle according to the diagnostic criteria that left ventricular end diastolic diameter (LVEDD) was $\geq 70 \mathrm{~mm}$, who underwent redo mitral valve surgery at our center from January 2006 to January 2019 were analyzed. We divided all patients into minimally invasive beating heart technique group $(n=30)$ and conventional median thoracotomy arrested heart technique group $(n=50)$ according to the surgical methods. Preoperative, intraoperative, and postoperative variables were compared between two groups.

Results: Minimally invasive beating heart technique compared to the conventional median thoracotomy arrested heart technique for redo mitral valve surgery in the cardiac patients with giant left ventricle had significant differences in operation time $(P=0.002)$, cardiopulmonary bypass $(\mathrm{CPB})$ time $(P<0.001)$, intraoperative blood loss $(P<0.001)$, postoperative transfusion ratio $(P=0.01)$, postoperative transfusion amount $(P<0.001)$, postoperative drainage volume $(P=0.001)$, extubation time $(P=0.04)$, intensive care unit (ICU) stay time $(P=0.04)$ and postoperative hospital stay time $(P<0.001)$, but no significant differences in re-exploration for bleeding, postoperative 30-day mortality, postoperative complications, and six months postoperative echocardiographic parameters.

Conclusions: Using the method of minimally invasive beating heart technique for redo mitral valve surgery in the cardiac patients with giant left ventricle is feasible, effective, reliable and cosmetic, meanwhile reduce the operation time and CPB time, decrease the transfusion ratio and transfusion amount, shorten postoperative ICU stay and hospital stay time, promote the early extubation so that accelerate the patients' early recovery.

\section{Background}

With the increasing number of cardiac surgery, more and more cases of mitral valve reoperations are made because of various reasons, such as perivalvular leakage, prosthesis dysfunction, rheumatic valve disease, infective endocarditis, perivalvular tissue hyperplasia, bioprosthetic valve decay. These patients tend to have a long course of disease, this could eventually lead to left ventricular enlargement and poor cardiac function. Especially for the patients with giant left ventricle according to the diagnostic criteria that left ventricular end diastolic diameter (LVEDD) is $\geq 70 \mathrm{~mm}$, redo mitral valve surgery represents a clinical challenge due to a higher rate of perioperative morbidity and mortality. In recent years, with the development and improvement of the cardiopulmonary bypass (CPB), the methods of operation, intraoperative myocardial protection and perioperative management, the operation effect of the large left ventricular valve disease was significantly improved. Formerly majority of cardiac surgeons preferred to choose original surgical approach through a median resternotomy for redo valve operations so that inevitably encountered risk of graft injuries, hemorrhage, the presence of dense adhesions, and complex 
valve exposure. Resternotomy may also be complicated in patients who had chest radiotherapy or previous sternal wound infections or in patients with vascular structures (ascending aorta, brachiocephalic vein,right ventricle and bypass vessels) that lie directly behind the sternum. Recently minimally invasive beating heart technique for redo cardic surgery had been safely performed successfully[1-7], which combined the availability and the advantage of a right-sided minithoracotomy approach without resternotomy and beating heart technique without aortic cross-clamping and cardiac arrest. The beating heart technique can interfere with the mechanisms of ischemia-reperfusion injury[8,9] that may be advantageous particularly in patients with poor left ventricular functions [10-14]. The patients with giant left ventricle tend to merge poor heart function, we assume that such patients benefit from this operation. However, so far not seen minimally invasive beating heart technique for redo mitral valve surgery in patients with giant left ventricle at home and abroad for details. In the present study, we analyze primarily the feasibility and efficacy of minimally invasive beating heart technique by comparing the preoperative, intraoperative, and postoperative variables of conventional median thoracotomy arrested heart technique for redo mitral valve surgery in the cardiac patients with giant left ventricle.

\section{Materials And Methods}

\section{Patients}

This study was approved by the Research Ethics Committee of the First Affiliated Hospital of Zhengzhou University. Eighty cardiac patients with giant left ventricle according to the diagnostic criteria that LVEDD was $\geq 70 \mathrm{~mm}$, who underwent redo mitral valve surgery at our center from January 2006 to January 2019 were analyzed. If the patient had significant aortic regurgitation (the effective regurgitate orifice area greater than $1 \mathrm{~cm}^{2}$ ) and (or) reoperation for immediate or early surgical failures (same hospital admission or less than 30 days) was excluded. From August 2011 to January 2019, thirty patients with giant left ventricle were reoperated through a minimally invasive approach in the right fourth intercostal space without aortic cross-clamping (minimally invasive beating heart group). There were eighteen males and twelve females (mean age of $60.7 \pm 6.8$ years); the average body surface area (BSA) was (1.74 \pm 0.08 ) $\mathrm{m}^{2}$; the average body mass index (BMI) was $(23.6 \pm 0.9) \mathrm{kg} / \mathrm{m}^{2}$; logistic EuroSCORE predicted risk of operative mortality was $15.3 \% \pm 5.4 \%$; the average left ventricular ejection fraction (LVEF) was $0.43 \pm$ 0.08 ; the average LVEDD was $(75.8 \pm 3.9) \mathrm{mm}$; the average cardiothoracic ratio was $(0.72 \pm 0.05)$.

Selected patients were associated with other comorbidities, such as congestive heart failure (6 cases), hypertension (13 cases), chronic obstructive pulmonary disease (COPD) (2 cases), diabetes mellitus (2 cases), pulmonary hypertension (6 cases), atrial fibrillation (13 cases), cerebrovascular disease (1 case), moderate or greater tricuspid regurgitation (TR) (8 cases). Previous cardiac surgery methods were as follows: 8 cases of mitral valvuloplasty (MVP), 8 cases of mitral valve replacement (MVR), 4 cases of MVR and tricuspid valvuloplasty (TVP), 4 cases of MVP and TVP, 4 cases of MVR and aortic valve replacement (AVR), 2 cases of coronary artery bypass grafting (CABG). The reoperation reasons were as follows: 6 cases of mitral valve perivalvular leakage, 2 cases of mitral valve prosthesis dysfunction, 4 cases of rheumatic mitral valve disease, 6 cases of infective endocarditis, 8 cases of mitral valve 
perivalvular tissue hyperplasia, 4 cases of mitral bioprosthetic valve decay. From January 2006 to January 2019, fifty patients with giant left ventricle were reoperated through conventional median sternotomy with aortic cross-clamping and cardioplegic arrest (median thoracotomy arrested heart group). There were thirty-three males and seventeen females (mean age of $60.2 \pm 7.6$ years). Detailed preoperative demographics and patient characteristics are shown in Table 1.

\section{Minimally invasive beating heart technique}

Under general anesthesia with a double lumen endotracheal intubation, patients were positioned with the right side of the chest slightly elevated. Transesophageal echocardiography (TEE) were performed and external defibrillation pads were placed in all patients. Sites of arterial and venous cannulation are described in Table 2. We preferred to use peripheral cannulation through the right internal jugular vein, right femoral vein, and right femoral artery after systemic heparinization, under TEE guidance. Especially the right internal jugular vein was percutaneously cannulated to better improve venous drainage for patients additionally undergoing tricuspid valve surgery. If only implemented the single femoral venous cannula that was inserted well into the superior vena cava (SVC) in order to avoid dislocation of the tip out of the SVC after left atrial retraction. CPB was established with vacuum assisted venous drainage with $30 \mathrm{mmHg}$ negative pressure followed by a right anterolateral minithoracotomy through a 4 to $6 \mathrm{~cm}$ incision on the anterior axillary line via the right fourth intercostal space. The incision should be avoid as far as possible the breast for female patients. It had better to make a curved incision from the lower edge of the breast to protect the breast tissue. A rib spreader (Geister, Germany) was placed after a soft tissue retractor was inserted the incision. Then made two small incisions (1 cm in length) in the second and sixth intercostal space on the midaxillary line respectively. Carbon dioxide through the incision in the second intercostal space at 5 liters per minute was continuously insufflated into the chest throughout the procedure to displace intracardiac air. A left ventricular drainage tube was placed through the incision in the sixth intercostal space. Under naked eye euthyphoria sheared longitudinally pericardium along anterior $2 \mathrm{~cm}$ of the right phrenic nerve, fixed anterior pericardium on the edge of the incision by silk thread and pulled posterior pericardium to posterolateral chest wall through two mininal incisions by suture. The aorta was not cannulated or clamped. At the beginning of experience, the patient's body temperature was cooled to 27 or $28^{\circ} \mathrm{C}$ to induce ventricular fibrillation. Subsequently, temperature was maintained between 32 and $33^{\circ} \mathrm{C}$ to allow an operation on the empty beating heart[5,7]. An aortic vent was always under continuous suction in the ascending aorta to evacuate air. With the heart perfused and beating, the left atrium was then immediately opened through interatrial groove or a trans-septal incision after a longitudinal right atriotomy in case of tricuspid surgery. For tricuspid surgery, dissociated the SVC and inferior vena cava (IVC) and completely blocked vena cava. In particular, we used 4-0 Prolene line with gasket to do the internal purse suture at SVC and IVC to right atrium opening that completely blocked vena cava, which avoided secondary injury of free vena cava because of fatal adhesion. An atrial retractor was placed through the fifth or sixth intercostal space parasternally and the left atriotomy was retracted anteriorly as a mass retraction. A left ventricular drainage tube was inserted right pulmonary vein that was used to maintain a clear operative field. The MVP or MVR was performed with interrupted 
pledgetted 2-0 braided polyester mattress sutures under direct vision. The tricuspid valvuloplasty was performed by using the ring annuloplasty method. For coexisting paroxysmal or persistent atrial fibrillation, we preferred to use monopolar radiofrequency ablation maze approach that was easier in the minimally invasive setting. To prevent possible left atrial air embolism, the left atrium was filled with backflow of blood keeping the prosthetic or native valve open before closing the atriotomy. TEE was used to confirm proper valve and ventricular function and to ensure complete removal of air. The patient was disconnected from CPB after appropriate reperfusion and was decannulated. Placed pericardial drainage and chest drainage tubes, closed the femoral longitudinal incision and the thoracotomy in a standard fashion.

\section{Statistical analysis}

Continuous variables are expressed as the mean \pm standard deviation or median and the range of values (if non-normally distributed) and categoric variables are presented as proportions. Differences between groups were assessed by using the Pearson's chi-square test or two-tailed p-value Fisher exact test where appropriate for categoric variables, the unpaired two-tailed $t$ test for continuous variables (Mann-Whitney $U$ test for non-normally distributed continuous variables). All statistical analyses were performed by using the IBM SPSS software package (version 20.0; SPSS, Chicago, IL, USA). A value of $p<0.05$ was considered statistically significant.

\section{Results}

\section{Demographics and preoperative and intraoperative characteristics}

The patient demographics and preoperative characteristics in both groups were similar and not statistically significant differences (Table 1). The patients for redo mitral valve surgery tended to have older age, most of them were male and had a history of smoking. Previous cardiac surgeries were primarily mitral valve related diseases operations. The reoperation reasons were mainly mitral valve perivalvular leakage, mitral valve prosthesis dysfunction, rheumatic mitral valve disease, infective endocarditis, mitral valve perivalvular tissue hyperplasia, mitral bioprosthetic valve decay. The patients with giant left ventricle tended to have relatively low LVEF (0.43 \pm 0.08 vs $0.45 \pm 0.09)$, New York Heart Association (NYHA) functional class above II accounted for the most part (66.7\% vs $64.0 \%$ ). Namely, these patients were more likely to have significant comorbidities at the time of surgery, for example, congestive heart failure, hypertension, COPD, diabetes mellitus, pulmonary hypertension, atrial fibrillation, cerebrovascular disease and moderate or greater TR, therefore mean preoperative logistic EuroSCORE predicted risk of operative mortality was quite high $(15.3 \% \pm 5.4 \%$ vs $14.8 \% \pm 5.4 \%)$.

Intraoperatively, the operation times ( $3.75 \pm 0.45$ vs $4.17 \pm 0.62$ hours, $P=0.002)$ and CPB times $(130.2 \pm$ 19.3 vs $165.2 \pm 27.6$ minutes, $P<0.001)$ were shorter in the minimally invasive beating heart group, blood loss (515 \pm 188 vs $697 \pm 222 \mathrm{ml}, P<0.001$ ) was obviously decreased compared with median thoracotomy arrested heart group (Table 2). There were 1 and 4 patients who required an intra-aortic balloon pump $(I A B P)$ to wean from extra-corporeal circulation in either group. One patient in the minimally invasive 
beating heart group underwent conversion to sternotomy because of extensive adhesions on the chest wall so that unable to single lung ventilation, at which time an aortic cross-clamp was placed. There were 1 and 4 patients who needed to re-exploration for bleeding in either group, but no statistically significance $(3.3 \%$ vs $8.0 \%, P=0.72)$. Arterial cannulation and myocardial protection strategies differed between the two groups. In the minimally invasive beating heart group, femoral arterial cannulation was almost used in 29 patients (96.7\%), with the rest one undergoing ascending aortic cannulation (3.3\%). On the contrary, in the median thoracotomy arrested heart group, ascending aortic cannulation was used in $88.0 \%$ of patients $(n=44)$, and 6 patients $(12 \%)$ underwent femoral arterial cannulation. Myocardial protection was achieved with ventricular fibrillation or superficial hypothermic empty beating heart $\left(32.1 \pm 0.46^{\circ} \mathrm{C}\right.$ core temperature) in beating heart surgery and performed with transthoracic aortic cross-clamp and cold crystalloid cardioplegia $\left(29.0 \pm 1.47^{\circ} \mathrm{C}\right.$ core temperature) in arrested heart. The distribution of valvular procedures performed and concomitant operative procedures is presented in Table 2. The most of patients for redo mitral valve surgery were performed MVR $(86.7 \%$ vs $86.0 \%, P=0.93)$. There were 8 and 14 patients who had concomitant moderate or greater TR in either group were all performed TVP by using the ring annuloplasty method. For coexisting paroxysmal or persistent atrial fibrillation, 7 patients were used monopolar radiofrequency ablation improved maze approach in the minimally invasive setting, however, 4 patients were used monopolar and 11 patients were used bipolar radiofrequency ablation improved maze approach in the conventional median thoracotomy.

\section{Postoperative clinical outcomes}

The early 30-day mortality was lower in the minimally invasive beating heart group, although not significant difference (6.7\% [n=2] vs $14.0 \%$ [ $n=7], P=0.52)$ (Table 3). Causes of death were multiple organ dysfunction syndrome (MODS) $(n=2)$ and coexist low cardiac output syndrome (LCOS) $(n=1)$ in the minimally invasive beating heart group. The postoperative complications in the minimally invasive beating heart group were all lower than that in the median thoracotomy arrested heart group, such as stroke ( $0 \%$ vs $6.0 \%)$, acute renal failure (6.7\% vs $14.0 \%)$, liver dysfunction $(6.7 \%$ vs $10.0 \%)$, pulmonary complications (6.7\% vs $12.0 \%)$, MODS (6.7\% vs $14.0 \%)$, LCOS (3.3\% vs $10.0 \%)$, ventricular fibrillation (6.7\% vs $14.0 \%$ ), cardiac tamponade (3.3\% vs $6.0 \%$ ), cardiac arrest ( $0 \%$ vs $4.0 \%$ ), atrioventricular block (3.3\% vs $8.0 \%$ ), superficial wound infection ( $0 \%$ vs $4.0 \%$ ), while there were no statistical significances. There was no statistical difference between the two groups in postoperative atrial fibrillation after radiofrequency ablation ( $36.7 \%$ vs $36.0 \%, P=0.95)$. Fortunately, minimally invasive beating heart technique compared to the conventional median thoracotomy arrested heart technique for redo mitral valve surgery in the cardiac patients with giant left ventricle had significant differences in postoperative transfusion ratio ( $66.7 \%$ vs $90.0 \%, P=0.01)$, median postoperative transfusion amount ( 2.0 vs $5.0 \mathrm{U}$, $P<0.001$ ), median postoperative drainage volume (450 vs $800 \mathrm{ml}, P=0.001$ ), median extubation time (13 vs 17 hours, $P=0.04$ ), median ICU stay time ( 16.5 vs 24.5 hours, $P=0.04$ ) and median postoperative hospital stay time ( 6 vs 9 days, $P<0.001$ ). With patient agreement, we obtained the six months postoperative echocardiograms, which were available in all patients through consulting related cases data and telephone follow-up. The six months postoperative echocardiographic parameters (LVEDD, 
LVEF, cardiothoracic ratio, NYHA functional class) had a marked improvement compared with the preoperative circumstances, but there were no statistical significance between the two groups.

\section{Discussion}

With technological advancements of cardiac surgery and extended lifespans of patients undergoing cardiac surgery, the number of redo cardiac operation continues to increase. Redo procedures usually involve sternal reentry, which has the potential for hazardous injuries to the important structures and subsequent morbidity and mortality[15]. Furthermore, conventional cardiac arrest may predispose the dilated myocardium to ischemia-reperfusion injury and postoperative low cardiac output in the patients who have poor ventricular function and giant left ventricle for a long-standing valve diseases. Against the situation mentioned above, minimally invasive beating heart technique for redo mitral valve surgery in patients with giant left ventricle has emerged in this environment. More and more reports had confirmed that minimally invasive beating heart technique for redo cardic surgery could be safely performed successfully[3-7].

In our study, the intraoperative blood loss, postoperative transfusion ratio, postoperative transfusion amount and postoperative drainage volume were all reduced significantly in minimally invasive beating heart compared to that in median thoracotomy. The greatest potential benefit of a right mini-thoracotomy is the avoidance of sternal re-entry and limited dissection of adhesions, avoiding the risk of injury to cardiac structures or patent grafts, and limiting the amount of postoperative bleeding[16]. With that in mind, it was not difficult to understand that the patients benefited reduced blood loss and less transfusions from minimally invasive beating heart. Moreover, the operation time and the CPB time in minimally invasive beating heart group were significantly shorter, whereas the shorter CPB time also reduced the need for perioperative blood transfusion, which was more important for redo patients. Of course, less CPB time decreased the release of inflammatory cytokines that contributed to a lower incidence of other comorbidities such as renal and liver insufficiency, pulmonary disease. Postoperative acute renal failure, liver dysfunction, MODS and pulmonary complications all declined in the minimally invasive beating heart, while there were no statistical significances. But there was statistical significance in the extubation time, the patients gained an early extubation which had a certain significance in preventing postoperative pulmonary infection and ventilator-induced lung injury. All the advantages we mentioned above significantly shortened postoperative ICU stay and hospital stay time so that accelerated the patients' faster recovery. Romano and colleagues[6]concluded that redo right thoracotomy mitral valve surgery on the beating heart is associated with shorter bypass time, less transfusion requirements, shorter postoperative ventilation, and lower mortality. The mortality of patients with giant left ventricle was very high, the first cardic surgery death rate was $9 \%$ through median thoracotomy in the study of D.HAN[17], the redo cardic surgery mortality would have been higher understandably. In our study, the logistic EuroSCORE predicted risk of operative mortality was high to $15.3 \% \pm 5.4 \%$. Fortunately, the postoperative 30 -day mortality was $6.7 \%$ in minimally invasive beating heart group that was significantly lower than the expected mortality predicted by the logistic EuroSCORE, and it was less than $14 \%$ in median thoracotomy arrested heart group, but there was no significant 
difference. Botta and colleagues[5]reported that two patients died in both groups (mortality was 4.5\%) from multiorgan failure and CPB time was respectively 166 and 163 minutes, they asserted that there was no difference in biochemical or clinical outcomes from conventional surgery using aortic clamping and cardioplegic techniques. In our study, the six months postoperative echocardiographic parameters (LVEDD, LVEF, cardiothoracic ratio, NYHA functional class) had a marked improvement compared with the preoperative circumstances, but there were no statistical significances between the two groups. Murzi and colleagues[18]reported that thirty-day mortality was $4.1 \%$ and reoperative mitral valve surgery could be safely performed through a right minithoracotomy with good early and late outcomes.

Currently, possible beating heart alternatives are performing the redo mitral valve operation with aortic endoballoon clamp[19] or an unclamped aorta[6,12,13] on the empty beating heart or ventricular fibrillation/fibrillating arrest while myocardial protection is achieved through continuous coronary perfusion. The big advantage of this continuous myocardial perfusion procedure is to decrease or eliminate myocardial damage caused by ischemia-reperfusion injury which follows standard manoeuvres of aortic cross clamping and clamp release[6, 8,20], which may be advantageous particularly in patients with poor left ventricular functions $[10-13,21]$. In the animal model, the morphology and function of the myocardial cells in ventricular fibrillation or sinus rhythm beating heart were all better than that in aortic occlusion during $\mathrm{CPB}[22]$. In this study, we initially started to take the beating heart alternative with ventricular fibrillation, subsequently, we adopted beating heart technique with the empty beating heart that temperature was maintained between 32 and $33^{\circ} \mathrm{C}$. Some researchers believed that beating heart alternative with ventricular fibrillation approach was inferior to the empty beating heart owing to its reduction oxygen delivery to the subendocardium and the consequent suboptimal myocardial protection $[6,9,21]$. As normothermic perfusion was maintained, risk of coagulopathy was reduced and blood loss was usually much less than with hypothermic ventricular fibrillation $[4,6]$.Therefore, this empty beating heart approach would be better helpful in patients with giant left ventricle tend to merge poor heart function. By keeping the heart beating, myocardial edema is decreased and function may be maintained, which may be of particular importance in these patients with already impaired ventricular function. These were good explanations for the postoperative morbidity of LCOS and ventricular fibrillation was lower in the minimally invasive beating heart group. As we all known, LCOS and ventricular fibrillation are leading causes of death in patients with giant left ventricle. This helps to further explain the lower postoperative 30-day mortality.

This beating heart method increased returned blood volume that influenced operation field, and increased cardiac attraction that contributed to corresponding blood damage augment[19]. It might be contraindicated if there was significant aortic insufficiency resulted in difficult to maintain a relatively bloodless operative field and sufficiently coronary perfusion. In our study, the patient had significant aortic regurgitation that the effective regurgitate orifice area greater than $1 \mathrm{~cm}^{2}$ was excluded. In the event of concomitant mild aortic insufficiency, flows on CPB can be decreased and systemic temperature lowered in other studies[5]. Teruya and colleagues[4] used 2 drop-in suckers through the left atrial incision in this particular case, a left ventricular vent via the apex using mini-left thoracotomy was useful in 
preventing distention of the left ventricle. We obtained satisfactory results through a left ventricular drainage tube that was inserted right pulmonary vein. Meanwhile, we adopted remifentanil[23]and landiolol[24]that were helpful for heart rate reduction to prevent regurgitant blood flow from coming up to the operative field for very slight aortic insufficiency. Though we got a good view of surgery through the unremitting effects, it was difficult to perform MVP relative to MVR while the heart was kept perfused and beating. Therefore we had a very high probability $(86.7 \%)$ of valve replacement that was similar to other studies[5]. On the other hand, the patients with large left ventricular heart valve disease in general had poor preoperative cardiac function and serious pathological lesion, so the surgery was mostly performed valve replacement or carried out valvuloplasty cautiously[17].In the implementation of MVR, mitral posterior and subvalvular apparatus should be preserved as far as possible so that maximized to protect the left ventricular tension ring function and avoid the further expansion of the left ventricular transverse diameter[25].

It was noteworthy that the saline injection test was never been applied because it would pressurize the ventricle especially in valve repair. Another concern is the possibility of air embolism. An aortic vent was always under continuous suction in the ascending aorta and carbon dioxide was continuously insufflated into the chest to displace intracardiac air in this research. Additionally, the left atrium was filled with backflow of blood keeping the prosthetic or native valve open and the lungs were reinsufflated before closing the atriotomy to prevent possible left atrial air embolism. TEE was also used to ensure complete removal of air. We had achieved good results that there were no neurological complications caused by air embolism through using the methods mentioned above, which also had been confirmed in many other reports[7, 26]. In addition, minimally invasive beating heart approach can avoid systemic embolization caused by aortic clamping when severe aortic calcification. Some groups have reported increased stroke rates in patients undergoing the right minithoracotomy approach with retrograde arterial perfusion for redo mitral valve operation[27], but others hold the contrary opinion[28].

The limitations to the use of minimally invasive beating heart approach are mainly related to a prolonged learning curve that can increase the risk of patients at new centres and to the cost of the devices. At the beginning, there was one patient who needed to re-exploration for chest wall bleeding due to lack of experience. This kind of stupid mistake no longer occurred with the improvement of operation skill and experience. Although the operation of patient with giant left ventricle is difficult through minimally invasive thoracotomy, we should not ignore the great advantage of this method. As long as the lung function can be satisfied with one lung ventilation, we should try to take this kind of operation for the patients with giant left ventricle undergoing reoperation. In addition, there are several limitations that it is a small sample size and retrospective study at a single center in our study, long-term follow up data are also needed regarding the durability of this technique. Large-scale multi-center randomized controlled clinical trails are warranted to further validate the potential benefits and the limitations of this technique.

\section{Conclusions}


In conclusion, minimally invasive beating heart technique has the potential to combine the benefits of minimally invasive access and continuous myocardial perfusion, which is feasible, effective, reliable and cosmetic for redo mitral valve surgery in the cardiac patients with giant left ventricle. However, we could not demonstrate significant superiority in postoperative 30-day mortality and postoperative complications than could be achieved with a conventional median sternotomy and aortic cross-clamping and cardioplegic arrest. But the main advantages of this technique are that it avoid extensive surgical dissection, reduce the operation time and CPB time, decrease the transfusion ratio and transfusion amount, shorten postoperative ICU stay and hospital stay time, promote the early extubation so that accelerate the patients' early recovery.

\section{Abbreviations}

\section{LVEDD}

left ventricular end diastolic diameter

CPB

cardiopulmonary bypass

ICU

intensive care unit

BSA

body surface area

$\mathrm{BMI}$

body mass index

LVEF

left ventricular ejection fraction

COPD

chronic obstructive pulmonary disease

TR

tricuspid regurgitation

MVP

mitral valvuloplasty

MVR

mitral valve replacement

TVP

tricuspid valvuloplasty

AVR

aortic valve replacement

CABG

coronary artery bypass grafting

TEE

Transesophageal echocardiography 
SVC

superior vena cava

IVC

inferior vena cava

NYHA

New York Heart Association

IABP

intra-aortic balloon pump

MODS

multiple organ dysfunction syndrome

LCOS

low cardiac output syndrome

\section{Declarations}

\section{Ethics approval and consent to participate}

The study protocol was approved by the Research Ethics Committee of the First Affiliated Hospital of Zhengzhou University.

\section{Consent for publication}

Not applicable.

\section{Availability of data and materials}

The datasets used and/or analyzed during the current study are available from the corresponding author on reasonable request.

\section{Competing interests}

The authors declare that they have no competing interests.

\section{Funding}

Not applicable.

\section{Authors' contributions}

Hang Zhang and Chao Liu contributed to the conception and design of the work. Hang Zhang and Huashan Xu contributed to conception, design, data analysis and editing the manuscript. Hang Zhang, Bing Wen and Wen-zeng Zhao contributed to data acquisition, statistical analysis and interpretation of the data. Hang Zhang and Chao Liu contributed to the revision of the manuscript. All authors have approved the final draft of the manuscript. 
Acknowledgements

Not applicable.

\section{Authors' information}

\section{Affiliations}

Department of Cardiovascular Surgery, The First Affiliated Hospital of Zhengzhou University, Zhengzhou,450052, Henan, China

Hang Zhang,Hua-shan Xu,Bing Wen,Wen-zeng Zhao,Chao Liu

\section{Corresponding author}

Correspondence to Hang Zhang.

\section{References}

1.

Grinberg D, Pozzi M, Bordet M, et al. Minithoracotomy and Beating Heart Strategy for Mitral Surgery in Secondary Mitral Regurgitation. Thorac Cardiovasc Surg. 2019.

2.

Xu RB, Rahnavardi M, Nadal M, et al. Beating heart minimally invasive mitral valve surgery in patients with previous sternotomy: the operative technique and early outcomes. Open Heart. 2018;5(1):e000749. 3.

Kim HR, Kim GS, Yoo JS, Lee JW. Minimally invasive approach for redo mitral valve replacement: no aortic cross-clamping and no cardioplegia. Korean J Thorac Cardiovasc Surg. 2015;48(2):126-8. 4.

Nakamura T, Izutani H, Sekiya N, Nakazato T, Sawa Y. Beating heart mitral valve repair for a patient with previous coronary bypass: a case report and review of the literature. J Cardiothorac Surg. 2013;8:187. 5.

Botta L, Cannata A, Fratto P, et al. The role of the minimally invasive beating heart technique in reoperative valve surgery. J Card Surg. 2012;27(1):24-8.

6.

Romano MA, Haft JW, Pagani FD, Bolling SF. Beating heart surgery via right thoracotomy for reoperative mitral valve surgery: a safe and effective operative alternative. J Thorac Cardiovasc Surg. 2012;144(2):334-9.

7.

Kitamura T, Stuklis RG, Edwards J. Redo mitral valve operation via right minithoracotomy-"no touch" technique. Int Heart J. 2011;52(2):107-9.

8. 
Wang J, Liu H, Xiang B, et al. Keeping the heart empty and beating improves preservation of hypertrophied hearts for valve surgery. J Thorac Cardiovasc Surg. 2006;132(6):1314-20.

9.

Matsumoto Y, Watanabe G, Endo M, Sasaki H, Kasashima F, Kosugi I. Efficacy and safety of on-pump beating heart surgery for valvular disease. Ann Thorac Surg. 2002;74(3):678-83.

10.

Masroor S, Dance G, Angeli SJ. Beating heart video-assisted mitral valve surgery: a useful technique for high-risk patients. J Card Surg. 2009;24(3):312-4.

11.

Macedo FI, Carvalho EM, Hassan M, Ricci M, Gologorsky E, Salerno TA. Beating heart valve surgery in patients with low left ventricular ejection fraction. J Card Surg. 2010;25(3):267-71.

12.

Ghosh S, Jutley RS, Wraighte P, Shajar M, Naik SK. Beating-heart mitral valve surgery in patients with poor left ventricular function. J Heart Valve Dis. 2004;13(4):622-7. discussion 627-629.

13.

Durukan AB, Gurbuz HA, Tavlasoglu M, Ucar HI, Yorgancioglu C. Beating Heart Mitral Valve Replacement Surgery without Aortic Cross-Clamping via Right Thoracotomy in a Patient with Compromised Left Ventricular Functions. J Tehran Heart Cent. 2015;10(1):43-5.

14.

Kaplon RJ, Pham SM, Salerno TA. Beating-heart valvular surgery: a possible alternative for patients with severely compromised ventricular function. J Card Surg. 2002;17(2):170-2.

15.

Morales D, Williams E, John R. Is resternotomy in cardiac surgery still a problem? Interact Cardiovasc Thorac Surg. 2010;11(3):277-86.

16.

Botta L, Cannata A, Bruschi G, et al. Minimally invasive approach for redo mitral valve surgery. J Thorac Dis. 2013;5(Suppl 6):686-93.

17.

Han D, Zhang Y, Xue DM, Wang WL, Yan WJ. Valve replacement for valvular heart disease with giant left ventricle. Eur Rev Med Pharmacol Sci. 2015;19(16):3001-5.

18.

Murzi M, Miceli A, Di Stefano G, et al. Minimally invasive right thoracotomy approach for mitral valve surgery in patients with previous sternotomy: a single institution experience with 173 patients. $J$ Thorac Cardiovasc Surg. 2014;148(6):2763-8.

19.

Vallabhajosyula P, Wallen T, Pulsipher A, et al. Minimally Invasive Port Access Approach for Reoperations on the Mitral Valve. Ann Thorac Surg. 2015;100(1):68-73.

20.

Mo A, Lin H. Surgical correction of ruptured aneurysms of the sinus of Valsalva using on-pump beatingheart technique. J Cardiothorac Surg. 2010;5:37. 
21.

Atoui R, Bittira B, Morin JE, Cecere R. On-pump beating heart mitral valve repair in patients with patent bypass grafts and severe ischemic cardiomyopathy. Interact Cardiovasc Thorac Surg. 2009;9(1):138-40. 22.

White NJ, Leong BS, Brueckner J, et al. Coagulopathy during cardiac arrest and resuscitation in a swine model of electrically induced ventricular fibrillation. Resuscitation. 2011;82(7):925-31.

23.

Shu A, Zhan L, Fang $\mathrm{H}$, et al. Evaluation of remifentanil anesthesia for off-pump coronary artery bypass grafting surgery using heart rate variability. Exp Ther Med. 2013;6(1):253-9.

24.

Nakanishi K, Takeda S, Kim C, Kohda S, Sakamoto A. Postoperative atrial fibrillation in patients undergoing coronary artery bypass grafting or cardiac valve surgery: intraoperative use of landiolol. $\mathrm{J}$ Cardiothorac Surg. 2013;8:19.

25.

Reardon MJ, David TE. Mitral valve replacement with preservation of the subvalvular apparatus. Curr Opin Cardiol. 1999;14(2):104-10.

26.

Ricci M, Macedo FI, Suarez MR, Brown M, Alba J, Salerno TA. Multiple valve surgery with beating heart technique. Ann Thorac Surg. 2009;87(2):527-31.

27.

Crooke GA, Schwartz CF, Ribakove GH, et al. Retrograde arterial perfusion, not incision location, significantly increases the risk of stroke in reoperative mitral valve procedures. Ann Thorac Surg. 2010;89(3):723-9. discussion 729-730.

28.

Modi P, Chitwood WR. Jr. Retrograde femoral arterial perfusion and stroke risk during minimally invasive mitral valve surgery: is there cause for concern? Ann Cardiothorac Surg. 2013;2(6):E1.

\section{Tables}

Table 1. Preoperative Demographics and Patient Characteristics 


\begin{tabular}{|c|c|c|c|}
\hline Features & Minimally invasive beating heart $(\mathrm{n}=30)$ & $\begin{array}{l}\text { Median thoracotomy } \\
\text { arrested heart }(n=50)\end{array}$ & $P$ Value \\
\hline \multicolumn{4}{|l|}{ Demographics } \\
\hline Age\years $\square$ & $60.7 \pm 6.8$ & $60.2 \pm 7.6$ & 0.30 \\
\hline Male sex & $18(60.0 \%)$ & $33(66.0 \%)$ & 0.59 \\
\hline Smoker & $19(63.3 \%)$ & $34(68.0 \%)$ & 0.67 \\
\hline $\mathrm{BSA} \square \mathrm{m}^{2} \square$ & $1.74 \pm 0.08$ & $1.74 \pm 0.07$ & 0.61 \\
\hline $\mathrm{BMI} \square \mathrm{kg} / \mathrm{m}^{2} \square$ & $23.6 \pm 0.9$ & $24.0 \pm 1.0$ & 0.90 \\
\hline \multicolumn{4}{|l|}{ Comorbidities } \\
\hline Congestive heart failure & $6(20.0 \%)$ & $12(24.0 \%)$ & 0.68 \\
\hline Hypertension & $13(43.3 \%)$ & $25(50.0 \%)$ & 0.56 \\
\hline COPD & $2(6.7 \%)$ & $7(14.0 \%)$ & 0.52 \\
\hline Diabetes mellitus & $2(6.7 \%)$ & $6(12.0 \%)$ & 0.70 \\
\hline Pulmonary hypertension & $6(20.0 \%)$ & $15(30.0 \%)$ & 0.33 \\
\hline Atrial fibrillation & $13(43.3 \%)$ & $21(42.0 \%)$ & 0.91 \\
\hline Cerebrovascular disease & $1(3.3 \%)$ & $3(6.0 \%)$ & 1.0 \\
\hline Previous cardiac surgeries & & & 0.60 \\
\hline MVP & $8(26.7 \%)$ & $9(18.0 \%)$ & \\
\hline MVR & $8(26.7 \%)$ & $18(36.0 \%)$ & \\
\hline MVR+TVP & $4(13.3 \%)$ & $6(12.0 \%)$ & \\
\hline MVP+TVP & $4(13.3 \%)$ & $3(6.0 \%)$ & \\
\hline MVR+AVR & $4(13.3 \%)$ & $10(20.0 \%)$ & \\
\hline CABG & $2(6.7 \%)$ & $4(8.0 \%)$ & \\
\hline NYHA functional class & & & 0.64 \\
\hline I & $4(13.3 \%)$ & $3(6.0 \%)$ & \\
\hline II & $6(20.0 \%)$ & $15(30.0 \%)$ & \\
\hline III & $14(46.7 \%)$ & $18(36.0 \%)$ & \\
\hline IV & $6(20.0 \%)$ & $14(28.0 \%)$ & \\
\hline Logistic EuroSCORE & $15.3 \% \pm 5.4 \%$ & $14.8 \% \pm 5.4 \%$ & 0.61 \\
\hline Predominant valve lesion & & & 0.95 \\
\hline Perivalvular leakage & $6(20.0 \%)$ & $9(18.0 \%)$ & \\
\hline Prosthesis dysfunction & $2(6.7 \%)$ & $6(12.0 \%)$ & \\
\hline Rheumatic & $4(13.3 \%)$ & $6(12.0 \%)$ & \\
\hline Endocarditis & $6(20.0 \%)$ & $11(22.0 \%)$ & \\
\hline Perivalvular hyperplasia & $8(26.7 \%)$ & $9(18.0 \%)$ & \\
\hline Bioprosthetic valve decay & $4(13.3 \%)$ & $9(18.0 \%)$ & \\
\hline \multicolumn{4}{|l|}{ Echocardiography } \\
\hline LVEF & $0.43 \pm 0.08$ & $0.45 \pm 0.09$ & 0.27 \\
\hline $\mathrm{LVEDD} \square \mathrm{mm} \rrbracket$ & $75.8 \pm 3.9$ & $75.3 \pm 3.6$ & 0.52 \\
\hline $\mathrm{LVESD} \square \mathrm{mm} \square$ & $50.0 \pm 5.3$ & $49.2 \pm 4.8$ & 0.70 \\
\hline LVFS & $0.31 \pm 0.04$ & $0.32 \pm 0.04$ & 0.81 \\
\hline Cardiothoracic Ratio & $0.72 \pm 0.05$ & $0.71 \pm 0.05$ & 0.70 \\
\hline Moderate or greater TR & $8(26.7 \%)$ & $14(28.0 \%)$ & 0.90 \\
\hline
\end{tabular}

Note: Continuous variables are expressed as means \pm standard deviation.

Acronyms: BSA, body surface area; BMI, body mass index; COPD, chronic obstructive pulmonary disease; MVP, mitral valvuloplasty; MVR, mitral valve replacement;TVP, tricuspid valvuloplasty;AVR, aortic valve replacement; CABG, coronary artery bypass grafting; NYHA, New York Heart Association; LVEDD, left ventricular end diastolic diameter; LVESD, left ventricular end systolic diameter; LVEF, left ventricular ejection fraction; LVFS, left ventricular fraction shortening; TR, Tricuspid regurgitation.

Table 2. Intraoperative Patient Characteristics 


\begin{tabular}{|c|c|c|c|}
\hline Features & Minimally invasive beating heart $(\mathrm{n}=30)$ & $\begin{array}{l}\text { Median thoracotomy } \\
\text { arrested heart }(n=50)\end{array}$ & $P$ Value \\
\hline Operation time $\llbracket$ hours $\square$ & $3.75 \pm 0.45$ & $4.17 \pm 0.62$ & 0.002 \\
\hline Cross-clamp time $\llbracket$ minutes $\square$ & & $86.3 \pm 8.06$ & \\
\hline CPB time $\square$ minutes $\square$ & $130.2 \pm 19.3$ & $165.2 \pm 27.6$ & $<0.001$ \\
\hline Conversion to sternotomy & $1(3.3 \%)$ & & \\
\hline Re-exploration for bleeding & $1(3.3 \%)$ & $4(8.0 \%)$ & 0.72 \\
\hline Intraoperative IABP & $1(3.3 \%)$ & $4(8.0 \%)$ & 0.72 \\
\hline Blood loss $\square \mathrm{ml} \square$ & $515 \pm 188$ & $697 \pm 222$ & $<0.001$ \\
\hline Temperature during $\mathrm{CPB} \square{ }^{\circ} \mathrm{C} \square$ & $32.1 \pm 0.46$ & $29.0 \pm 1.47$ & $<0.001$ \\
\hline Arterial cannulation & & & $<0.001$ \\
\hline Ascending aorta & $1(3.3 \%)$ & $44(88.0 \%)$ & \\
\hline Femoral artery & $29(96.7 \%)$ & $6(12.0 \%)$ & \\
\hline \multicolumn{4}{|l|}{ Venous cannulation } \\
\hline Bicaval & $1(3.3 \%)$ & $44(88.0 \%)$ & $<0.001$ \\
\hline Femoral vein alone & $6(20.0 \%)$ & $6(12.0 \%)$ & \\
\hline Jugulo-femoral & $23(76.7 \%)$ & $0 \%$ & \\
\hline Type of MV operation & & & 0.93 \\
\hline MVR & $26(86.7 \%)$ & $43(86.0 \%)$ & \\
\hline MVP & $4(13.3 \%)$ & $7(14.0 \%)$ & \\
\hline TVP & $8(100 \%)$ & $14(100 \%)$ & 1.0 \\
\hline Radiofrequency ablation & $7(53.8 \%)$ & $15(71.4 \%)$ & 0.50 \\
\hline
\end{tabular}

Note: Continuous variables are expressed as means \pm standard deviation. Bold values represent $P$ values are considered to be statistically significant at $\square 0.05$.

Acronyms: CPB, cardiopulmonary bypass; IABP, intra-aortic balloon pump; MVP, mitral valvuloplasty; MVR, mitral valve replacement; TVP, tricuspid valvuloplasty; MV, mitral valve.

Table 3. Postoperative Clinical Outcomes

\begin{tabular}{|c|c|c|c|}
\hline Features & Minimally invasive beating heart $(\mathrm{n}=30)$ & $\begin{array}{l}\text { Median thoracotomy } \\
\text { arrested heart }(\mathrm{n}=50)\end{array}$ & $P$ Value \\
\hline $\begin{array}{l}\text { 30-day mortality } \\
\text { postoperative complications }\end{array}$ & $2(6.7 \%)$ & $7(14.0 \%)$ & 0.52 \\
\hline Stroke & $0 \%$ & $3(6.0 \%)$ & 1.0 \\
\hline Acute renal failure & $2(6.7 \%)$ & $7(14.0 \%)$ & 0.52 \\
\hline Liver dysfunction & $2(6.7 \%)$ & $5(10.0 \%)$ & 0.92 \\
\hline Pulmonary complications & $2(6.7 \%)$ & $6(12.0 \%)$ & 0.70 \\
\hline MODS & $2(6.7 \%)$ & $7(14.0 \%)$ & 0.52 \\
\hline LCOS & $1(3.3 \%)$ & $5(10.0 \%)$ & 0.51 \\
\hline Ventricular fibrillation & $2(6.7 \%)$ & $7(14.0 \%)$ & 0.52 \\
\hline Cardiac tamponade & $1(3.3 \%)$ & $3(6.0 \%)$ & 1.0 \\
\hline Cardiac arrest & $0 \%$ & $2(4.0 \%)$ & 0.53 \\
\hline Atrioventricular block & $1(3.3 \%)$ & $4(8.0 \%)$ & 0.72 \\
\hline Superficial wound infection & $0 \%$ & $2(4.0 \%)$ & 0.53 \\
\hline Atrial fibrillation & $11(36.7 \%)$ & $18(36.0 \%)$ & 0.95 \\
\hline Transfusion Ratio & $20(66.7 \%)$ & $45(90.0 \%)$ & 0.01 \\
\hline Transfusion AmountıU■ & $2.0(0 \sim 16)$ & $5.0(0 \sim 20)$ & $<0.001$ \\
\hline Drainage Volume $\llbracket \mathrm{ml} \square$ & $450(100 \sim 3000)$ & $800(250 \sim 4320)$ & 0.001 \\
\hline Extubation time $\llbracket$ hours $\square$ & $13(6 \sim 50)$ & $17(9 \sim 72)$ & 0.04 \\
\hline ICU stayロhours $\square$ & $16.5(11 \sim 58)$ & $24.5(13 \sim 80)$ & 0.04 \\
\hline Postoperative hospital stay $\llbracket$ days $\square$ & $6(5 \sim 28)$ & $9(5 \sim 45)$ & $<0.001$ \\
\hline \multicolumn{4}{|l|}{ Six months postoperative } \\
\hline $\mathrm{LVEDD} \llbracket \mathrm{mm} \rrbracket$ & $64.3 \pm 3.3$ & $64.4 \pm 4.2$ & 0.18 \\
\hline LVEF & $0.55 \pm 0.07$ & $0.53 \pm 0.08$ & 0.50 \\
\hline Cardiothoracic Ratio & $0.62 \pm 0.04$ & $0.63 \pm 0.05$ & 0.24 \\
\hline NYHA functional class & & & 0.33 \\
\hline I & $14(46.7 \%)$ & $18(36.0 \%)$ & \\
\hline II & $13(43.3 \%)$ & $25(50.0 \%)$ & \\
\hline III & $2(6.7 \%)$ & $4(8.0 \%)$ & \\
\hline IV & $1(3.3 \%)$ & $3(10.0 \%)$ & \\
\hline
\end{tabular}

Note: Continuous variables are expressed as means \pm standard deviation or medians with range. Bold values represent $P$ values are considered to be statistically significant at $\square 0.05$. 
Acronyms: LCOS, Low cardiac output syndrome; MODS, multiple organ dysfunction syndrome; ICU, intensive care unit; LVEDD, left ventricular end diastolic diameter; LVEF, left ventricular ejection fraction; NYHA, New York Heart Association 